\title{
A pilot randomized trial of high-dose caffeine therapy in preterm infants
}

\author{
Christopher McPherson ${ }^{1,2}$, Jeffrey J. Neil ${ }^{3}$, Tiong Han Tjoeng ${ }^{4}$, Roberta Pineda ${ }^{5,6}$ and Terrie E. Inder ${ }^{2}$
}

BACKGROUND: Standard-dose caffeine improves white matter microstructural development assessed by diffusion magnetic resonance imaging (MRI). We hypothesized that early high-dose caffeine would result in further improvement in white matter microstructural development.

METHODS: Seventy-four preterm infants ( $\leq 30 \mathrm{wk}$ gestational age) were randomly assigned to either a high ( $80 \mathrm{mg} / \mathrm{kg}$ i.v.) or standard ( $20 \mathrm{mg} / \mathrm{kg}$ i.v.) loading dose of caffeine citrate in the first $24 \mathrm{~h}$ of life. MRI and neurobehavioral testing were undertaken at term equivalent age. Infants returned at 2 y of age for developmental testing.

RESULTS: Clinical characteristics were similar between groups, with the exception of higher maternal age in the high-dose caffeine group. There was an increased incidence of cerebellar hemorrhage in infants randomized to high-dose caffeine (36 vs. $10 \%, P=0.03)$. Infants in the high-dose caffeine group also demonstrated more hypertonicity $(P=0.02)$ and more deviant neurologic signs $(P=0.04)$ at term equivalent age. Diffusion measures at term equivalent age and developmental outcomes at 2 y of age did not differ between groups.

CONCLUSION: Preterm infants randomized to early high-dose caffeine had a higher incidence of cerebellar injury with subsequent alterations in early motor performance. The results of this pilot trial discourage a larger randomized controlled trial.

A pnea of prematurity occurs in a high proportion of infants born prematurely $(1,2)$. Caffeine reduces the frequency of apnea and the need for mechanical ventilation. At standard doses $(20 \mathrm{mg} / \mathrm{kg}$ caffeine citrate loading dose followed by $5-10 \mathrm{mg} / \mathrm{kg}$ daily), caffeine improves survival and lowers rates of cerebral palsy, motor delay, cognitive deficits, and visual perceptual problems in very-low-birth-weight infants (3-5). Interestingly, diffusion changes consistent with improved white matter microstructural development have been observed on magnetic resonance imaging (MRI) in infants randomized to standard-dose caffeine (6). Of note, this previous large study randomized infants during the first $10 \mathrm{~d}$ of life at the time of recurrent apnea or extubation, with a median age at randomization of $3 \mathrm{~d}$. It has been hypothesized that earlier administration of caffeine, prior to the timing of greatest vulnerability to white matter injury, may have greater neurologic benefit. Neonatologists have extrapolated from these data to use caffeine in very preterm infants as a neuroprotective agent from birth.

The beneficial effects of standard-dose caffeine also led to the investigation of high-dose caffeine. A single, randomized controlled trial suggested that high-dose caffeine citrate $(80 \mathrm{mg} / \mathrm{kg}$ load followed by $20 \mathrm{mg} / \mathrm{kg}$ daily) had positive effects on shortterm respiratory outcomes and childhood cognitive development $(7,8)$. However, no studies to date have investigated the effect of high-dose caffeine, prophylactically administered at the peak of white matter vulnerability, on brain development in addition to clinical and developmental outcomes.

The objective of this study was to examine the effects of a high vs. a standard loading dose of caffeine citrate, given to preterm infants within $24 \mathrm{~h}$ of birth, on clinical outcomes, brain structure, early neurobehavior during the neonatal period, and developmental outcome at $2 \mathrm{y}$. We hypothesized that early high-dose caffeine would result in improved white matter microstructural development at term equivalent age on diffusion MRI. Additionally, we hypothesized that early highdose caffeine would result in reduced ventilatory support, a reduction in white matter injury, and improved developmental outcome.

\section{RESULTS}

One-hundred eligible infants were admitted during the study period (November 2008-June 2010). Seventy-four infants (74\%) were randomized (Figure 1). There were no differences in the baseline characteristics (gestational age, gender, and birth weight) of the infants enrolled compared to those not enrolled. Thirty-seven infants (50\%) were randomized to highdose caffeine and 37 infants (50\%) to standard-dose caffeine. Demographics and perinatal factors were similar between groups, with the exception of higher maternal age in infants randomized to high-dose caffeine (Table 1). No study infants had caffeine withheld because of toxicity. Duration of caffeine therapy was not different between groups (postmenstrual age at discontinuation: high-dose $34.9 \pm 2.6$ wk vs. standard-dose 


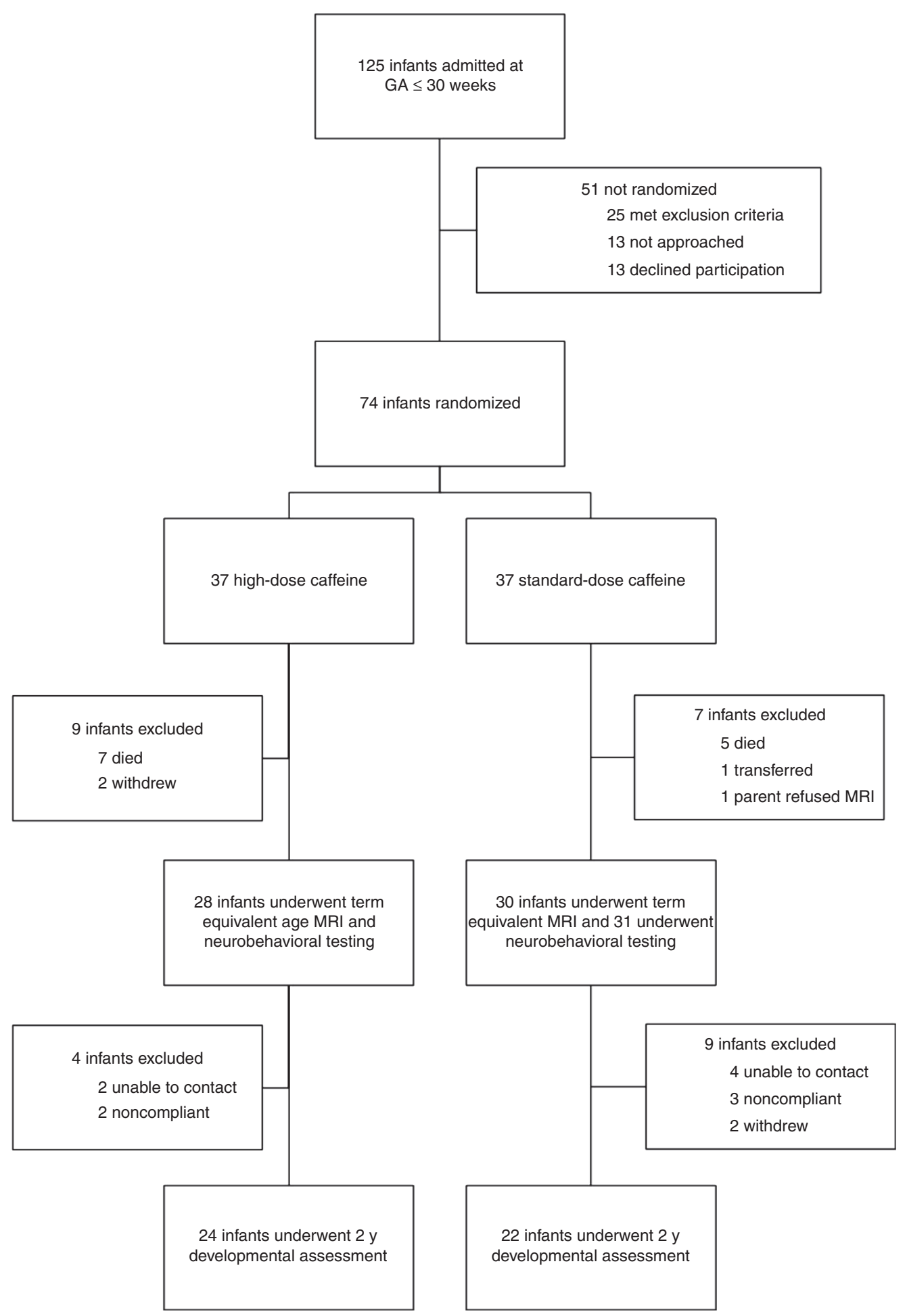

Figure 1. Subject eligibility, recruitment, and follow-up. Number of infants who were eligible for the study, randomly assigned to receive high-dose or standard-dose caffeine citrate, and followed at term equivalent age and 2 y corrected age.

$34.2 \pm 1.9$ wk, $P=0.21)$. Clinical outcomes and drug exposures were similar between groups (Table 2).

\section{Qualitative Brain Injury}

There were no differences in the incidence of intraventricular hemorrhage or periventricular leukomalacia, assessed by cranial ultrasounds (CUS), between groups (Table 3). Of the 74 infants enrolled in the study, 12 infants died (7 in the high-dose group; 5 in the standard-dose group). Two infants withdrew and one infant transferred (Figure 1). Thus, 59 infants remained in the study at term equivalent age (TEA). One infant did not undergo an MRI due to parent refusal. MRI was obtained at TEA age in 28 infants (76\%) randomized to high-dose caffeine and 30 infants $(81 \%)$ randomized 
Table 1. Demographics and perinatal factors

\begin{tabular}{|c|c|c|c|}
\hline Characteristics & $\begin{array}{c}\text { High-dose } \\
\text { caffeine }(n=37)\end{array}$ & $\begin{array}{l}\text { Standard-dose } \\
\text { caffeine }(n=37)\end{array}$ & $\begin{array}{c}P \\
\text { value }\end{array}$ \\
\hline Gestational age, weeks & $26.3 \pm 1.9$ & $26.8 \pm 1.8$ & 0.28 \\
\hline Birth weight, $g$ & $872 \pm 257$ & $949 \pm 245$ & 0.19 \\
\hline $\begin{array}{l}\text { Growth restriction weight } \\
\text { (z-score }<-2 \text { SD), } n(\%)\end{array}$ & $3(8)$ & $2(5)$ & $>0.99$ \\
\hline $\begin{array}{l}\text { Growth restriction OFC } \\
\text { (z-score }<-2 \text { SD), } n(\%)\end{array}$ & $5(14)$ & $1(3)$ & 0.20 \\
\hline Male gender, $n(\%)$ & $19(51)$ & $24(65)$ & 0.24 \\
\hline $\begin{array}{l}\text { Clinical risk index for } \\
\text { babies score }\end{array}$ & $4.7 \pm 4.1$ & $3.9 \pm 3.5$ & 0.34 \\
\hline Race & & & 0.42 \\
\hline African American, $n$ (\%) & $18(49)$ & $23(62)$ & \\
\hline Caucasian, $n(\%)$ & $17(46)$ & $12(34)$ & \\
\hline Maternal age, years & $29.0 \pm 7.5$ & $25.4 \pm 6.6$ & 0.03 \\
\hline Alcohol use, $n(\%)$ & 0 & $4(11)$ & 0.12 \\
\hline Illicit drug use, $n(\%)$ & $3(8)$ & $1(3)$ & 0.13 \\
\hline Social risk score & $3.5 \pm 1.1$ & $3.9 \pm 1.5$ & 0.36 \\
\hline Antenatal steroids, $n(\%)$ & $26(70)$ & $27(73)$ & 0.80 \\
\hline Chorioamnionitis, $n$ (\%) & $11(30)$ & $15(41)$ & 0.33 \\
\hline Vaginal delivery, $n$ (\%) & $9(24)$ & $11(30)$ & 0.60 \\
\hline
\end{tabular}

to standard-dose caffeine. There was no difference in the incidence of white matter, gray matter, or deep nuclear gray matter injury between groups at TEA. In infants randomized to high-dose caffeine, there was a higher incidence of cerebellar hemorrhage ( 36 vs. $10 \%$, OR 5.0 (95\% CI: $1.2-20.7$ ), $P=0.03$ ) and cerebellar hemorrhage or death (49 vs. $23 \%$, OR $3.2(95 \%$ CI: 1.1-8.9), $P=0.03)$. On univariate analysis, gestational age $(P=0.01)$, clinical risk index for babies score $(P=0.06)$, patent ductus arteriosus (PDA) requiring treatment $(P=0.01)$, cumulative dose of fentanyl in the first $7 \mathrm{~d}(P<0.001)$, and early vasopressor exposure $(P=0.02)$ correlated with cerebellar hemorrhage. The association between high-dose caffeine and cerebellar hemorrhage persisted after adjustment for these factors $(\beta=0.29,95 \%$ CI: $0.05-0.44, P=0.02)$.

\section{Brain Metrics, Volumes, and Diffusion}

There were no differences in body weight or head circumference between groups at MRI scan (bodyweight $\mathrm{z}$-score highdose -1.26 vs. standard-dose $-1.26, P>0.99$; occipitofrontal circumference $\mathrm{z}$-score -0.82 vs. $-0.49, P=0.33$ ). There were no differences between groups in brain growth, as measured by brain metrics $(n=58)$ or volumes $(n=18)$ (Table 4$)$. There were no differences between groups in apparent diffusion coefficient (ADC) or fractional anisotropy on diffusion imaging in any analyzed brain regions (Table 5).

\section{Neurobehavioral Outcomes at TEA}

Twenty-eight infants (76\%) randomized to high-dose caffeine and 31 infants (84\%) randomized to standard-dose caffeine
Table 2. Clinical characteristics

\begin{tabular}{|c|c|c|c|}
\hline & $\begin{array}{c}\text { High-dose } \\
\text { caffeine }(n=37)\end{array}$ & $\begin{array}{l}\text { Standard-dose } \\
\text { caffeine }(n=37)\end{array}$ & $\begin{array}{c}P \\
\text { value }\end{array}$ \\
\hline $\begin{array}{l}\text { Exogenous surfactant } \\
\text { therapy, } n(\%)\end{array}$ & $37(100)$ & $37(100)$ & $>0.99$ \\
\hline Ventilator days & $4(1-22)$ & $3(1-22)$ & 0.95 \\
\hline $\begin{array}{l}\text { Oxygen requirement at } 36 \mathrm{wk} \\
\text { postmenstrual age, } n(\%)\end{array}$ & $19(51)$ & $18(49)$ & 0.82 \\
\hline $\begin{array}{l}\text { Total parenteral nutrition } \\
\text { days }\end{array}$ & $19(11-38)$ & $17(11-35)$ & 0.71 \\
\hline $\begin{array}{l}\text { Patent ductus arteriosus } \\
\text { requiring treatment, } n(\%)\end{array}$ & $20(54)$ & $20(54)$ & $>0.99$ \\
\hline Necrotizing enterocolitis, $n(\%)$ & $6(16)$ & $5(14)$ & 0.74 \\
\hline $\begin{array}{l}\text { Retinopathy of } \\
\text { prematurity } \geq \text { grade } 3, n(\%)\end{array}$ & $2(5)$ & $4(11)$ & 0.68 \\
\hline Dexamethasone, $n(\%)$ & $5(14)$ & $6(16)$ & 0.74 \\
\hline Hydrocortisone, $n(\%)$ & $14(38)$ & $9(24)$ & 0.21 \\
\hline Vasopressor hours & $1(0-67)$ & $0(0-11)$ & 0.05 \\
\hline $\begin{array}{l}\text { Vasopressor initiation } \\
\text { at }<120 \text { h of life, } n(\%)\end{array}$ & $7(19)$ & $8(22)$ & 0.77 \\
\hline Midazolam, $n(\%)$ & $10(27)$ & $8(22)$ & 0.79 \\
\hline Morphine, n(\%) & $5(14)$ & $9(24)$ & 0.24 \\
\hline Fentanyl, $n(\%)$ & $35(95)$ & $30(81)$ & 0.15 \\
\hline Death before discharge, $n$ (\%) & $7(19)$ & $5(14)$ & 0.53 \\
\hline
\end{tabular}

Values represent median (first quartile - third quartile).

underwent neurobehavioral testing at TEA (Table 6). Infants randomized to high-dose caffeine had higher hypertonia summary scores on the NICU Network Neurobehavioral Scale (NNNS) (2.3 vs. $1.5, P=0.02)$. On univariate analysis, gestational age at birth $(P=0.01)$ and cumulative fentanyl dose before TEA $(P=0.04)$ correlated with the NNNS hypertonia summary score. The association between caffeine group and hypertonia summary score persisted after controlling for these factors ( $\beta=0.29,95 \% \mathrm{CI}: 0.13-1.32, P=0.02)$. There were no other differences in NNNS summary scores between groups. On Dubowitz neurologic examination at TEA, infants randomized to high-dose caffeine had lower deviant signs compound optimality scores (assessment of hand posture, tremors, and startles; 1.1 vs. $1.5, P=0.04$ ). On univariate analysis, exposure to antenatal steroids correlated with the Dubowitz deviant signs compound optimality score $(P=0.02)$. The association between caffeine group and deviant signs compound optimality score persisted after controlling for antenatal steroid exposure ( $\beta=-0.29,95 \%$ CI: -0.95 to $-0.05, P=0.03$ ). All other Dubowitz compound optimality scores and the total optimality score were similar between groups. The Neonatal Oral Motor Assessment Scale (NOMAS) score was not different between groups.

\section{Developmental Assessment at 2 y}

Twenty-four infants ( $80 \%$ of survivors) randomized to highdose caffeine and 22 infants (69\% of survivors) randomized to standard-dose caffeine underwent developmental testing 
Table 3. Brain injury

\begin{tabular}{|c|c|c|c|}
\hline & $\begin{array}{l}\text { High-dose } \\
\text { caffeine } \\
(n=37)\end{array}$ & $\begin{array}{l}\text { Standard- } \\
\text { dose caffeine } \\
\quad(n=37)\end{array}$ & $P$ value \\
\hline $\begin{array}{l}\text { Any intraventricular } \\
\text { hemorrhage, } n(\%)\end{array}$ & $10(27)$ & $12(32)$ & 0.61 \\
\hline $\begin{array}{l}\text { Grade III/IV intraventricular } \\
\text { hemorrhage, } n(\%)\end{array}$ & $4(11)$ & $4(11)$ & $>0.99$ \\
\hline Periventricular leukomalacia, $n(\%)$ & $3(8)$ & $2(5)$ & 0.78 \\
\hline White matter injury, $n$ (\%) & $2(7)$ & $4(14)$ & 0.75 \\
\hline Cortical gray matter injury, $n(\%)^{\text {a }}$ & 0 & 0 & $>0.99$ \\
\hline Deep gray matter injury, $n(\%)^{\mathrm{a}}$ & 0 & $2(7)$ & 0.49 \\
\hline Cerebellar hemorrhage, $n(\%)^{\text {a }}$ & $10(36)$ & $3(10)$ & 0.03 \\
\hline Focal unilateral & $2(7)$ & $1(3)$ & \\
\hline Focal bilateral & $4(14)$ & $1(3)$ & \\
\hline Extensive unilateral & $3(11)$ & 0 & \\
\hline Extensive bilateral & $1(4)$ & $1(3)$ & \\
\hline $\begin{array}{l}\text { Death or cerebellar hemorrhage, } \\
n(\%)^{\mathrm{b}}\end{array}$ & $17(49)$ & $8(23)$ & 0.03 \\
\hline \multicolumn{4}{|c|}{ 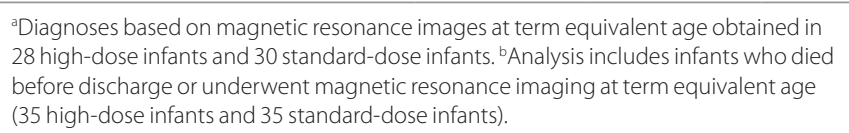 } \\
\hline
\end{tabular}

at 2 y of age (from March 2011 to November 2012). BayleyIII scores for cognitive (high-dose 85.6 vs. standard-dose $88.0, P=0.42)$, language ( 90.5 vs. $88.9, P=0.67)$, and motor (85.3 vs. $85.9, P=0.86$ ) development were not different between groups.

\section{DISCUSSION}

The data from this pilot, randomized trial suggest increased risk of cerebellar hemorrhage in preterm infants randomized to early high-dose caffeine. Early high-dose caffeine was also associated with subtle neurobehavioral differences at TEA, including increased tone and abnormal movements. There were no detectable differences in neurodevelopmental outcome at $2 \mathrm{y}$ of age among infants randomized to highvs. standard-dose caffeine therapy, although the study was not powered to detect benefit or detriment in long-term neurodevelopment.

The results of this pilot trial do not support our initial hypothesis that infants randomized to high-dose caffeine would demonstrate a reduction in white matter injury. Our results show no effect on white matter injury and a higher incidence of cerebellar hemorrhage in infants randomized to high-dose caffeine. The high incidence of brain injury in the current trial was not found in previous randomized trials of caffeine therapy. The Caffeine for Apnea of Prematurity (CAP) trial found no impact of standard-dose caffeine therapy on brain injury assessed by CUS (3). Similarly, a randomized trial comparing high-dose caffeine to standard doses found no difference in the incidence of brain injury assessed by CUS (7). Neither trial reported the incidence of cerebellar hemorrhage. It is possible that the incidence of cerebellar hemorrhage was
Table 4. Brain metrics and volumes

\begin{tabular}{|c|c|c|c|}
\hline & $\begin{array}{c}\text { High-dose } \\
\text { caffeine }(n=28)\end{array}$ & $\begin{array}{l}\text { Standard-dose } \\
\text { caffeine }(n=30)\end{array}$ & $P$ value \\
\hline d-Bifrontal diameter & $-15.0 \pm 4.8$ & $-14.7 \pm 6.1$ & 0.82 \\
\hline $\begin{array}{l}\text { d-Brain biparietal } \\
\text { diameter }\end{array}$ & $-14.4 \pm 4.4$ & $-13.8 \pm 4.4$ & 0.61 \\
\hline $\begin{array}{l}\text { Interhemispheric } \\
\text { distance }\end{array}$ & $3.8 \pm 1.5$ & $3.9 \pm 1.8$ & 0.73 \\
\hline $\begin{array}{l}\text { d-Transverse } \\
\text { cerebellar diameter }\end{array}$ & $-0.3 \pm 3.1$ & $0.3 \pm 2.8$ & 0.52 \\
\hline $\begin{array}{l}\text { Right ventricular } \\
\text { diameter }\end{array}$ & $7.8 \pm 1.6$ & $7.8 \pm 1.9$ & 0.95 \\
\hline $\begin{array}{l}\text { Left ventricular } \\
\text { diameter }\end{array}$ & $8.2 \pm 2.1$ & $8.2 \pm 1.6$ & 0.91 \\
\hline White matter volume ${ }^{a}$ & $136.7 \pm 26.7$ & $127.8 \pm 13.1$ & 0.36 \\
\hline Gray matter volume & $104.3 \pm 14.4$ & $103.9 \pm 26.7$ & 0.97 \\
\hline $\begin{array}{l}\text { Deep nuclear gray } \\
\text { matter volume }\end{array}$ & $23.0 \pm 2.2$ & $22.1 \pm 2.2$ & 0.39 \\
\hline Cerebellar volume ${ }^{\mathrm{a}}$ & $18.7 \pm 4.1$ & $16.2 \pm 2.4$ & 0.13 \\
\hline $\begin{array}{l}\text { Cerebrospinal fluid } \\
\text { volume }^{\mathrm{a}}\end{array}$ & $109.4 \pm 37.3$ & $104.6 \pm 17.2$ & 0.72 \\
\hline
\end{tabular}

underestimated in these trials, because of reliance on traditional CUS for detection (9). Studies utilizing posterolateral fontanel CUS or MRI, which are presumably more sensitive than conventional CUS, reveal a higher incidence of this lesion in preterm infants (10).

Severe cerebellar hemorrhage is a clinically important lesion associated with adverse neurodevelopmental outcome, but the pathophysiology has not yet been elucidated (11). The incidence of cerebellar hemorrhage is highly dependent on the degree of prematurity, with slight differences in maturation strikingly altering the risk for this form of brain injury (10). Cardiovascular factors, including compromised cerebral circulation and poor cerebrovascular autoregulation, may contribute to its multifactoral pathology (11). Standard loading and maintenance doses of caffeine increase cardiac index and blood pressure in preterm infants (12). Importantly, standard loading doses of caffeine do not alter cerebral blood flow velocity (13); while high loading doses significantly decrease cerebral blood flow velocity (14). Additionally, fluctuations in arterial blood pressure occur with asynchronous spontaneous breathing during mechanical ventilation (15). These fluctuations dramatically impact venous ciruclation and have been implicated in the causation of intraventricular hemorrhage $(16,17)$. This convergence of factors, in conjunction with pressure passive circulation known to occur in the preterm infant, may increase susceptibilty to hemorrhage within the cerebellum (18). Additionally, preclinical data suggest that brain injury may be aggravated by the absense of adenosine A2A receptors (19). Early, widespread, nonspecific antagonism of adenosine receptors may have been exaggerated with higher doses of caffeine, increasing risk in the susceptible cerebellum. 


\section{Articles | McPherson et al.}

Table 5. Diffusion

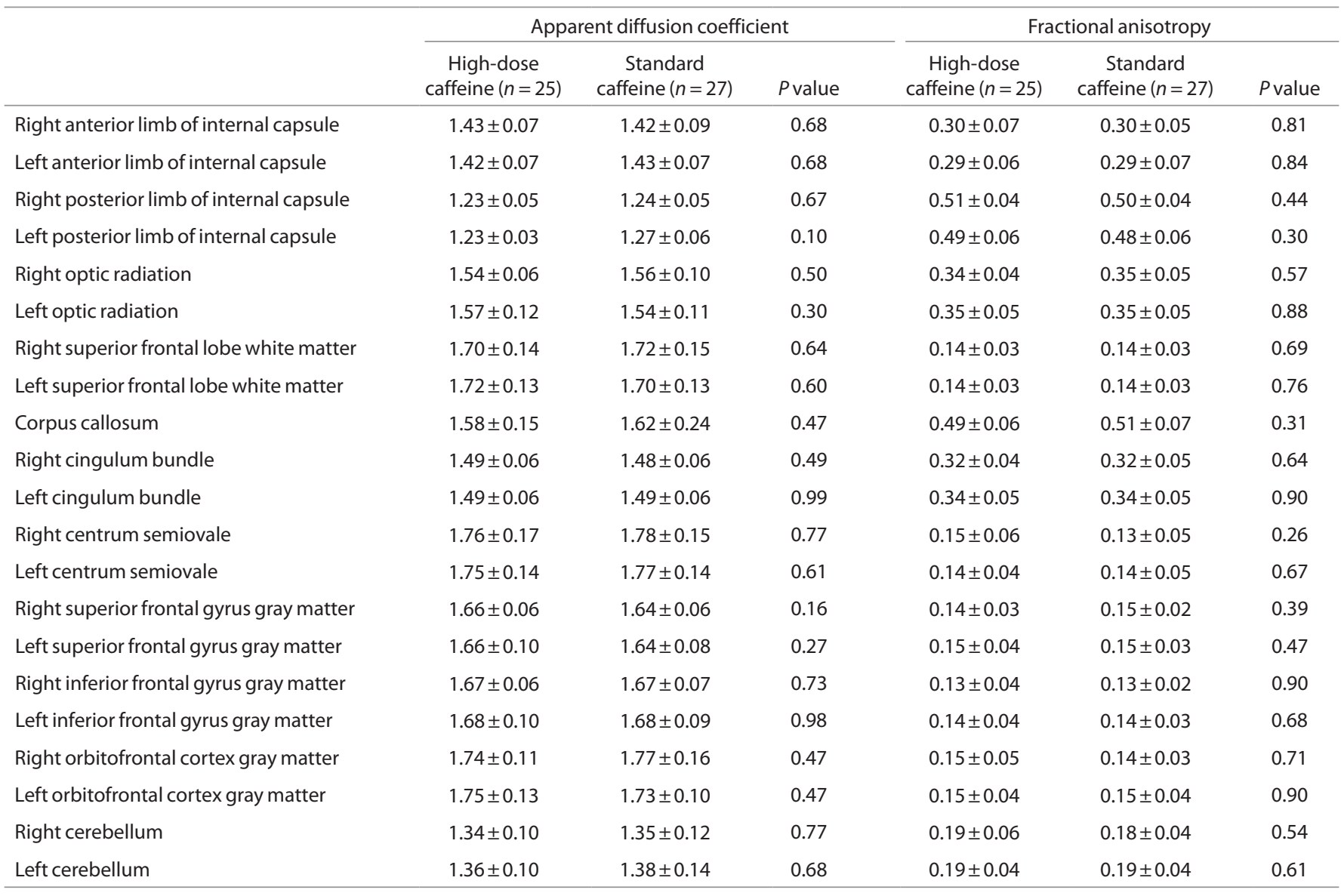

Values represent mean \pm SD.

We found no influence of high-dose caffeine on body or brain growth at TEA. Methylxanthine therapy increases oxygen consumption and energy expenditure, and the CAP trial demonstrated a detrimental effect of standard-dose caffeine therapy on early weight gain (3). Further, high-dose caffeine therapy prolonged the time required to regain birth weight compared to standard-dose caffeine (7). However, no difference in overall weight gain for the duration of caffeine therapy was found in either trial $(3,7)$. The data from the current trial support this finding, additionally suggesting that brain growth is not impaired by early exposure to high-dose caffeine therapy.

The results of this pilot trial do not support our initial hypothesis of improved microstructural development in preterm infants in response to high-dose caffeine therapy. This hypothesis was based on MRI analyses showing reduced diffusion in the superior brain regions of a subset of infants randomized to standard-dose caffeine therapy in the CAP trial (6). In the current trial, a higher loading dose of caffeine produced no observable differences in brain diffusion parameters.

Finally, infants who received high-dose caffeine exhibited increased tone and more deviant neurologic signs on standardized neurobehavioral assessment at TEA. The increased incidence of cerebellar hemorrhage represents the most likely etiology of these findings (11). Poor neonatal motor performance on standardized neurobehavioral exam has previously been reported with alterations in cerebellar structure (20). We will continue to follow this cohort to determine if behavioral differences persist at school-age. We did not detect differences in developmental outcome at $2 \mathrm{y}$ of age, consistent with the previous trial of high-dose caffeine therapy (8). However, we are not reassured by this null finding, as the study was not powered to detect differences at this stage of followup. We will evaluate this cohort to school-age with particular interest in impairments of executive function and affective or social disorders commonly associated with cerebellar abnormalities (11).

The findings of this trial must be treated with caution. As a pilot trial, the sample size was small and designed to determine the safety of a larger randomized trial. Although we hypothesized that high-dose caffeine may reduce ventilatory requirements and white matter injury, this pilot trial was only powered to detect differences in the primary outcome of microstructural brain development at TEA. However, the increased incidence of cerebellar hemorrhage in the very preterm infants randomized to high-dose caffeine indicates that caution should be exercised in considering further exploration of this dosing approach. Notably, this finding and other outcomes reported for this cohort beyond the primary endpoint must be viewed as post hoc and are reported for the sake of 
Table 6. Neurobehavioral outcomes at term equivalent age

\begin{tabular}{|c|c|c|c|}
\hline Characteristics & $\begin{array}{c}\text { High-dose } \\
\text { caffeine }(n=28)\end{array}$ & $\begin{array}{l}\text { Standard-dose } \\
\text { caffeine }(n=31)\end{array}$ & $P$ value \\
\hline \multicolumn{4}{|c|}{ NICU Network Neurobehavioral Scale } \\
\hline Attention & $3.1 \pm 1.9$ & $3.0 \pm 1.6$ & 0.91 \\
\hline Asymmetric reflexes & $2.5 \pm 1.9$ & $2.8 \pm 2.1$ & 0.51 \\
\hline Excitability & $5.9 \pm 2.9$ & $5.2 \pm 2.4$ & 0.31 \\
\hline Habituation & $3.4 \pm 3.9$ & $3.2 \pm 3.8$ & 0.82 \\
\hline Handling & $0.6 \pm 0.2$ & $0.6 \pm 0.3$ & 0.99 \\
\hline Hypertonicity & $2.3 \pm 1.3$ & $1.5 \pm 1.1$ & 0.02 \\
\hline Hypotonicity & $0.7 \pm 0.7$ & $0.8 \pm 0.9$ & 0.77 \\
\hline Lethargy & $6.8 \pm 3.0$ & $6.3 \pm 3.1$ & 0.51 \\
\hline Quality of movement & $3.3 \pm 0.9$ & $3.5 \pm 0.7$ & 0.26 \\
\hline Regulation & $4.3 \pm 0.9$ & $4.5 \pm 0.7$ & 0.29 \\
\hline Nonoptimal reflexes & $7.4 \pm 2.4$ & $7.1 \pm 2.3$ & 0.67 \\
\hline Stress/abstinence & $0.4 \pm 0.1$ & $0.4 \pm 0.1$ & 0.73 \\
\hline Arousal & $4.2 \pm 0.9$ & $4.1 \pm 1.0$ & 0.89 \\
\hline \multicolumn{4}{|c|}{ Dubowitz neurological examination } \\
\hline Total optimality score & $17.4 \pm 5.1$ & $18.7 \pm 4.3$ & 0.28 \\
\hline Tone & $5.1 \pm 2.2$ & $5.7 \pm 2.6$ & 0.39 \\
\hline Tone patterns & $2.9 \pm 0.9$ & $2.8 \pm 0.8$ & 0.89 \\
\hline Reflexes & $3.8 \pm 1.5$ & $4.0 \pm 1.2$ & 0.53 \\
\hline Movements & $1.1 \pm 0.9$ & $0.9 \pm 0.8$ & 0.37 \\
\hline Deviant signs & $1.1 \pm 0.8$ & $1.5 \pm 0.9$ & 0.04 \\
\hline Behavior & $3.4 \pm 1.4$ & $3.7 \pm 1.5$ & 0.43 \\
\hline $\begin{array}{l}\text { Neonatal oral motor } \\
\text { assessment scale score }\end{array}$ & $1.4 \pm 0.5$ & $1.4 \pm 0.5$ & 0.93 \\
\hline
\end{tabular}

Values represent mean \pm SD.

completeness. An additional limitation of this trial was conduction at a single center with unit-specific practices that may limit the external validity of our findings.

The results of this pilot trial discourage a larger randomized controlled trial. Additionally, the utilization of highdose caffeine therapy in clinical practice should be carefully considered, given the potential risks. Standard-dose caffeine, as described by the CAP trial, appears to be the best approach to reduce the duration of mechanical ventilation and improve neurodevelopmental outcomes of preterm infants.

\section{METHODS}

Patients

In this pilot, randomized, double-blind trial, preterm infants born at $\leq 30 \mathrm{wk}$ gestational age and admitted to the level III Neonatal Intensive Care Unit (NICU) at St. Louis Children's Hospital were enrolled within the first $24 \mathrm{~h}$ of life. Infants who had a known congenital anomaly, were moribund and/or in respiratory failure (defined as requiring $>80 \% \mathrm{FiO}_{2}$ for $6 \mathrm{~h}$ and/or having more than two inotropic drugs excluding hydrocortisone), or had severe brain injury (grade III-IV intraventricular hemorrhage) present in the first $24 \mathrm{~h}$ of life were excluded from the study. The study was approved by the Human Research Protection Office at Washington University in St. Louis and all parents provided signed informed consent. The trial was registered on www.ClinicalTrials.gov (NCT00809055).

\section{Study Drug Therapy}

Infants were randomized to high- or standard-dose caffeine therapy. Group assignment was performed by parallel 1:1 blocked randomization, generated by the dispensing pharmacist who was not involved in clinical care. The clinical and research team remained blinded to each infant's randomization until completion of developmental assessment at $2 \mathrm{y}$ of age.

High-dose caffeine therapy was administered intravenously as an initial loading dose of $40 \mathrm{mg} / \mathrm{kg}$ of caffeine citrate (Cafcit, Bedford Laboratories, Bedford, $\mathrm{OH}$ ) followed by $20 \mathrm{mg} / \mathrm{kg} 12 \mathrm{~h}$ later, then $10 \mathrm{mg} / \mathrm{kg}$ at 24 and $36 \mathrm{~h}$ after the initial dose $(80 \mathrm{mg} / \mathrm{kg}$ total over $36 \mathrm{~h}$ ). Standard-dose caffeine therapy was administered intravenously as $20 \mathrm{mg} / \mathrm{kg}$ of caffeine citrate followed by $10 \mathrm{mg} / \mathrm{kg} 24 \mathrm{~h}$ after the initial dose $(30 \mathrm{mg} / \mathrm{kg}$ total over $36 \mathrm{~h})$.

Caffeine therapy was initiated within $24 \mathrm{~h}$ of life. Caffeine doses were held for symptoms of caffeine toxicity, including tachycardia, jitteriness, tremors, seizures, and unexplained vomiting. All patients received caffeine citrate $10 \mathrm{mg} / \mathrm{kg}$ every $24 \mathrm{~h}$ beginning $48 \mathrm{~h}$ after the initial caffeine citrate dose and continued until resolution of apnea of prematurity per the attending physician.

\section{Data Collection}

Demographics (gender, gestational age, birth weight), perinatal factors (maternal age and race, maternal alcohol and illicit drug use, social risk score (20), antenatal steroids, mode of delivery, presence of chorioamnionitis, 5-min APGAR score, clinical risk index for babies score at birth) (21), and neonatal factors (days of total parenteral nutrition and ventilation; PDA requiring treatment; necrotizing enterocolitis defined as Bell's stage II-III (22); severe retinopathy of prematurity defined as grade 3 or 4 , culture proven sepsis; and total exposure to vasopressors, hydrocortisone, dexamethasone and sedatives) were collected from the electronic medical record. Treatments for PDA included ibuprofen, indomethacin, and surgical ligation. Weight and occipitofrontal circumference were recorded at birth and at the time of MRI to evaluate body and head growth, respectively.

\section{Evaluation of Brain Injury, Growth, and Development at Term} Equivalent Age

The presence of intraventricular hemorrhage and periventricular leukomalacia were evaluated by routine CUS obtained at intervals determined by the clinicians caring for the infant. At minimum, all patients received a CUS at 3 and $10 \mathrm{~d}$ of life. Intraventricular hemorrhage was graded as I-IV (23). At TEA (37-41 wk postmenstrual age), MRI was undertaken without sedation on a Magnetom Trio 3T scanner (Siemeens, Erlangen, Germany) (24). Brain injury was scored on $\mathrm{T}_{1}$ - and $\mathrm{T}_{2}$-weighted MRI studies in four areas (white matter, cortical gray matter, deep nuclear gray matter, and cerebellum) using methods previously described (25). Brain metrics were obtained through measurements (in $\mathrm{mm}$ ) of tissue and fluid spaces, including bifrontal, biparietal, transverse cerebellar, and right and left lateral ventricular diameters and interhemispheric distance, as previously described (26). The difference (d-) between each infant's regional measure and the mean regional measure in healthy fetal MRI was calculated to correct for postmenstrual age at the time of MRI scan (27). Volumetry was conducted on images of sufficient quality using Advanced Normalization Tools software (University of Pennsylvania, Philadelphia, PA), as previously described (28). Segmentations of cerebrospinal fluid, gray matter, deep nuclear gray matter, white matter, and cerebellum were manually edited by a data analyst and reviewed by a second analyst. Assessment of diffusion parameters was performed using Analyze (Mayo Foundation, Rochester, MN), with regions of interest manually placed bilaterally in the white matter (anterior and posterior limb of the internal capsule, optic radiation, superior frontal lobe, corpus callosum, cingulum bundle, centrum semiovale), gray matter (superior and inferior frontal gyrus, orbitofrontal cortex), and cerebellum. Cerebral regions of interest encompassed only white or gray matter, but cerebellar regions were mixed due to the fine structure of the cerebellar folia relative to the spatial resolution of the parametric maps. Values for ADC and fractional anisotropy were obtained.

Neurobehavioral outcomes at TEA were assessed in the NICU before discharge using the NNNS (29), Dubowitz Neurological 
Examination (30), and the NOMAS (31). TEA neurobehavioral testing was conducted by a single, licensed occupational therapist certified in all evaluations. The 13 summary scores of the NNNS, the total optimality score and the 6 compound optimality scores on the Dubowitz, and the NOMAS categorical score for neonatal feeding were investigated as outcomes.

\section{Developmental Assessment at 2 y}

Children returned at 2 y corrected age for a developmental assessment using the Bayley Scales of Infant and Toddler Development, Third Edition (32). All testers were blinded to study assignment and past medical history, including imaging findings. Language, motor, and cognitive composite scores were investigated as outcomes.

The primary outcome of this pilot trial was microstructural development at TEA, measured by ADC. Secondary outcome measures included short-term clinical outcomes, the rate of brain injury at TEA, and developmental outcomes at $2 \mathrm{y}$ of age.

\section{Statistical Analysis}

Statistical analyses were performed using SPSS 19 (SPSS, Chicago, IL). Differences across groups were explored using Student's $t$-tests, Mann-Whitney $U$-tests, and chi-squared analyses. To further explore significant differences between groups, logistic and linear regression models were employed, relating caffeine group to outcome measures with adjustment for potential covariates. Potential covariates were identified by investigating associations between baseline and clinical factors with the outcome variable tested, and those that were associated $(P<0.1)$ were included in the regression model. A sample size of 56 infants was required to detect a $5 \%$ difference in ADC in a single region of interest with $80 \%$ power and $\alpha=0.05$. Seventy-four infants were randomized assuming $20 \%$ loss to follow-up prior to TEA.

\section{ACKOWLEDGMENTS}

The authors thank Divyen Shah, Claudine Vavasseur, Karen Lukas, Jessica Conners, Rachel Paul, Tara Smyser, Jim Alexopoulous, Jeannette Kenley, Reggie Lee, Joseph Ackerman Jr., Lauren Reynolds, Anthony Barton, Christopher Smyser, Cynthia Rogers, Cynthia Ortinau, Michael Wallendorf, Jiajing Chen, and Amit Mathur for their assistance in the execution of this study. We also wish to acknowledge Nathalie Bednarek and Joshua Shimony for their assistance in image analysis.

\section{STATEMENT OF FINANCIAL SUPPORT}

This study was supported by the National Institute of Child Health and Development (R01 HD057098; K12 HD055931-06), the Intellectual and Developmental Disabilities Research Center at Washington University in St. Louis (NIH/NICHD P30 HD062171), and the Doris Duke Charitable Foundation (New York, NY).

Disclosure: The authors have no conflicts of interest to disclose.

\section{REFERENCES}

1. Barrington K, Finer N. The natural history of the appearance of apnea of prematurity. Pediatr Res 1991;29(4 Pt 1):372-5.

2. Henderson-Smart DJ, De Paoli AG. Methylxanthine treatment for apnoea in preterm infants. Cochrane Database Syst Rev 2010:CD000140.

3. Schmidt B, Roberts RS, Davis P, et al.; Caffeine for Apnea of Prematurity Trial Group. Caffeine therapy for apnea of prematurity. N Engl J Med 2006;354:2112-21.

4. Schmidt B, Roberts RS, Davis P, et al.; Caffeine for Apnea of Prematurity Trial Group. Long-term effects of caffeine therapy for apnea of prematurity. N Engl J Med 2007;357:1893-902.

5. Schmidt B, Anderson PJ, Doyle LW, et al.; Caffeine for Apnea of Prematurity (CAP) Trial Investigators. Survival without disability to age 5 years after neonatal caffeine therapy for apnea of prematurity. JAMA 2012;307:275-82.

6. Doyle LW, Cheong J, Hunt RW, et al. Caffeine and brain development in very preterm infants. Ann Neurol 2010;68:734-42.

7. Steer P, Flenady V, Shearman A, et al.; Caffeine Collaborative Study Group Steering Group. High dose caffeine citrate for extubation of preterm infants: a randomised controlled trial. Arch Dis Child Fetal Neonatal Ed 2004;89:F499-503.
8. Gray PH, Flenady VJ, Charles BG, Steer PA; Caffeine Collaborative Study Group. Caffeine citrate for very preterm infants: Effects on development, temperament and behaviour. J Paediatr Child Health 2011;47:167-72.

9. Steggerda SJ, Leijser LM, Wiggers-de Bruïne FT, van der Grond J, Walther FJ, van Wezel-Meijler G. Cerebellar injury in preterm infants: incidence and findings on US and MR images. Radiology 2009;252:190-9.

10. Limperopoulos C, Benson CB, Bassan H, et al. Cerebellar hemorrhage in the preterm infant: ultrasonographic findings and risk factors. Pediatrics 2005;116:717-24.

11. Volpe JJ. Cerebellum of the premature infant: rapidly developing, vulnerable, clinically important. J Child Neurol 2009;24:1085-104.

12. Soloveychik V, Bin-Nun A, Ionchev A, Sriram S, Meadow W. Acute hemodynamic effects of caffeine administration in premature infants. J Perinatol 2009;29:205-8.

13. Saliba E, Autret E, Gold F, Bloc D, Pourcelot L, Laugier J. Effect of caffeine on cerebral blood flow velocity in preterm infants. Biol Neonate 1989;56:198-203.

14. Hoecker C, Nelle M, Poeschl J, Beedgen B, Linderkamp O. Caffeine impairs cerebral and intestinal blood flow velocity in preterm infants. Pediatrics 2002;109:784-7.

15. Perlman J, Thach B. Respiratory origin of fluctuations in arterial blood pressure in premature infants with respiratory distress syndrome. Pediatrics 1988;81:399-403.

16. Perlman JM, Volpe JJ. Are venous circulatory abnormalities important in the pathogenesis of hemorrhagic and/or ischemic cerebral injury? Pediatrics 1987;80:705-11.

17. Perlman JM, McMenamin JB, Volpe JJ. Fluctuating cerebral blood-flow velocity in respiratory-distress syndrome. Relation to the development of intraventricular hemorrhage. N Engl J Med 1983;309:204-9.

18. Greisen G. Autoregulation of cerebral blood flow in newborn babies. Early Hum Dev 2005;81:423-8.

19. Adén U, Halldner L, Lagercrantz H, Dalmau I, Ledent C, Fredholm BB. Aggravated brain damage after hypoxic ischemia in immature adenosine A2A knockout mice. Stroke 2003;34:739-44.

20. Sanz-Cortes M, Egaña-Ugrinovic G, Zupan R, Figueras F, Gratacos E. Brainstem and cerebellar differences and their association with neurobehavior in term small-for-gestational-age fetuses assessed by fetal MRI. Am J Obstet Gynecol 2014;210:452.e1-8.

21. The International Neonatal Network. The CRIB (clinical risk index for babies) score: a tool for assessing initial neonatal risk and comparing performance of neonatal intensive care units. Lancet 1993;342:193-8.

22. Bell MJ, Ternberg JL, Feigin RD, et al. Neonatal necrotizing enterocolitis. Therapeutic decisions based upon clinical staging. Ann Surg 1978;187:1-7.

23. Volpe JJ. Neurology of the Newborn. 5th edn. Philadelphia: Saunders/Elsevier, 2008. pp. 541.

24. Mathur AM, Neil JJ, McKinstry RC, Inder TE. Transport, monitoring, and successful brain MR imaging in unsedated neonates. Pediatr Radiol 2008;38:260-4.

25. Kidokoro H, Neil JJ, Inder TE. New MR imaging assessment tool to define brain abnormalities in very preterm infants at term. AJNR Am J Neuroradiol 2013;34:2208-14.

26. Nguyen The Tich S, Anderson PJ, Shimony JS, Hunt RW, Doyle LW, Inder TE. A novel quantitative simple brain metric using MR imaging for preterm infants. AJNR Am J Neuroradiol 2009;30:125-31.

27. Garel C. MRI of the Fetal Brain: Normal Development and Cerebral Pathologies. New York: Springer, 2004. pp. 35-114.

28. Klein A, Ghosh SS, Avants B, et al. Evaluation of volume-based and surface-based brain image registration methods. Neuroimage 2010;51: 214-20.

29. Lester BM, Tronick E. NICU Network Neurobehavioral Scale (NNNS) Manual. Baltimore: Paul H. Brookes Pub. Co., 2005.

30. Dubowitz L, Mercuri E, Dubowitz V. An optimality score for the neurologic examination of the term newborn. J Pediatr 1998;133:406-16.

31. Palmer MM, Crawley K, Blanco IA. Neonatal Oral-Motor Assessment scale: a reliability study. J Perinatol 1993;13:28-35.

32. Bayley N. Bayley Scales of Infant and Toddler Development. 3rd edition. Oxford, UK: Pearson Assessment, 2005. 